\title{
Cross cultural adaptation and validation of a Spanish version of the lower limb functional index
}

\author{
Antonio I Cuesta-Vargas ${ }^{1,2^{*}}$, Charles P Gabel ${ }^{3}$ and Paul Bennett ${ }^{2}$
}

\begin{abstract}
Background: The Lower Limb Functional Index (LLFI) is a relatively recently published regional outcome measure. The development article showed the LLFI had robust and valid clinimetric properties with sound psychometric and practical characteristics when compared to the Lower Limb Extremity Scale (LEFS) criterion standard.

Objective: The purpose of this study was cross cultural adaptation and validation of the LLFI Spanish-version (LLFI-Sp) in a Spanish population.

Methods: A two stage observational study was conducted. The LLFI was initially cross-culturally adapted to Spanish through double forward and single backward translation; then subsequently validated for the psychometric characteristics of validity, internal consistency, reliability, error score and factor structure. Participants $(n=136)$ with various lower limb conditions of $>12$ weeks duration completed the LLFI-Sp, Western Ontario and McMaster University Osteoarthritis Index (WOMAC) and the Euroqol Health Questionnaire 5 Dimensions (EQ-5D-3 L). The full sample was employed to determine internal consistency, concurrent criterion validity, construct validity and factor structure; a subgroup $(n=45)$ determined reliability at seven days concurrently completing a global rating of change scale.

Results: The LLFI-Sp demonstrated high but not excessive internal consistency $(a=0.91)$ and high reliability (ICC $=0.96)$. The factor structure was one-dimensional which supported the construct validity. Criterion validity with the WOMAC was strong $(r=0.77)$ and with the EQ-5D-3 L fair and inversely correlated $(r=-0.62)$. The study limitations included the lack of longitudinal data and the determination of responsiveness.

Conclusions: The LLFI-Sp supports the findings of the original English version as being a valid lower limb regional outcome measure. It demonstrated similar psychometric properties for internal consistency, validity, reliability, error score and factor structure.
\end{abstract}

Keywords: Lower limb, Psychometrics, Outcome assessment, Spanish

\section{Introduction}

Patient reported outcome (PRO) measures $[1,2]$ are an integral part and process of the management of a patient's health. These tools are primarily used to objectively determine any response or change in a patient's status as a consequence of natural healing or the use of an intervention [3]. In this way there is a rapid

\footnotetext{
* Correspondence: acuesta.var@gmail.com

'Departamento de Psiquiatría y Fisioterapia, Facultad de Ciencias de la Salud, Universidad de Malaga, Andalucia Tech, Instituto de Biomedicina de Malaga (IBIMA), Grupo de Clinimetria (AE-14), Málaga, Spain

${ }^{2}$ School of Clinical Science, Faculty of Health at the Queensland University of Technology, Brisbane, Australia

Full list of author information is available at the end of the article
}

assimilation and understanding by the clinicians' and researchers' of how function and symptoms have changed in response to an intervention on a condition or disease and what effect this has had on the patient's capabilities [4]. The progression of this patient focused model has seen a gradual shift over the last two decades away from condition or disease specific measures and towards region specific PROs $[5,6]$. These regional tools reflect a change in status in the three key kinetic-chain regions of the upper and lower $[7,8]$ limbs and the spine [9].

For the kinetic-region of the lower limb, various instruments have been designed to measure and evaluate symptomatology as a single kinetic chain $[7,10-15]$ while 
others have focused on joints or conditions, particularly for the hip and knee [16-20]. Both regional and condition specific tools are not only used to indicate the effectiveness of an intervention but can also assist in guiding the decision process on what treatments to continue, adopt or change. They also assist in the determination of pre- and post-operative comparison of status and subsequent monitoring of the patient and their recovery during rehabilitation [7]. Generic health related questionnaires such as the Euroqol Health Questionnaire 5 Dimensions (EQ-5D-3 L) mix a wide range of qualityof-life dimensions and include a sixth question on overall perceived health-related status. These scales may not provide a complete picture of a particular functional component. Instead the questionnaire's constructs aim to measure the patient's overall health status and consequently can serve as a criterion-related validity indicator of general health.

Numerous lower-limb patient reported outcome measures assess function for specific joints [21-25], joint conditions [26-29], or region-specific conditions [30-33]. However, there is limited consensus regarding which tools to use $[7,16]$. The most commonly advocated and employed lower limb PROs are the regional Lower Extremity Functional Scale (LEFS) [10] and the diseasespecific Western Ontario and McMaster Universities (WOMAC) questionnaire [20,34].

Both tools are widely used with translations into several languages. For the LEFS this includes Portuguese, Persian and Dutch, however no validated Spanish version is available. For the WOMAC, a Spanish translated version has been adapted [17] and validated in a chronic population [20]. Despite being developed as a disease specific PRO and shown to have lower clinimetric capacity than the LEFS [34], the WOMAC has served as a regional PRO [34-36]. The WOMAC has multiple translations and by consequence, though not ideal, it is currently the only potentially applicable lower limb regional criterion PRO tool that is validated and available in Spanish $[19,20,34]$ where the psychometric properties were compared to the LEFS [37].

The Lower Limb Functional Index (LLFI) is another recent example of a lower limb regional PRO. The LLFI was published in 2012 and accepted by various professional and governmental organisations [7] as well as independent outcome assessment agencies [38]. The LLFI was developed in line with the WHO-ICF [39] and used a combination of constructs that included body functions, body structures, activities and participation and environmental factors. The LLFI was shown to have strong clinimetric properties [6] that were preferable to those of the LEFS [7]. These properties included the psychometric characteristics of reliability, validity, responsiveness, error measurement and internal consistency.
From the practical characteristics perspective [7] it showed brevity, ready transferability to a 100 -point scale, ease and rapidity of completion and scoring, low missing responses and suitable readability. The LLFI was also shown [7] to have a single factor structure [36]. In view of the findings of preferable clinimetric properties for this lower limb PRO [7], translation to a Spanish version was warranted. This was supported by findings that comparable PROs in the functional index series for the upper limb [40] and spine [9] were found to be preferable to other advocated English criterion PROs within their development studies and in independent research including translated versions in French and Spanish [41].

A Spanish version of the LLFI had not been adapted and validated to date. This is significant given that Spanish is one of the five most spoken languages and the second widest geographically spoken [42]. Consequently a Spanish version, the LLFI-Sp, was developed to meet this need. Therefore the aims of this paper were: to describe the process of translation and cross-cultural adaptation of the original LLFI to Spanish; and to subsequently assess the five critical psychometric properties of reliability, onedimensional factor structure, internal consistency, measurement error and concurrent criterion validity for clinical use with Spanish speakers. The hypothesis of the present study is that new LLFI-Sp must show a strong relationship with WOMAC as the region specific criterion.

\section{Materials and methods \\ Design}

This was a two stage observational study. Stage 1 involved the initial Spanish translation and cross-cultural adaptation of the LLFI [7]. Stage 2 involved a prospective evaluation of the LLFI-Sp's critical psychometric properties. This included the concurrent completion, in a Spanish physical therapy outpatients' population, of the LLFI-Sp with a lower limb regional criterion, the WOMAC [19], and a general health questionnaire, the EQ-5D-3 L [43]. The WOMAC provided a criterion specific comparison for the lower limb while the EQ-5D$3 \mathrm{~L}$ enabled a clarification and criterion standard for comparison of the participants' health status. Two assessors performed the initial and subsequent assessment of data obtained from the questionnaires that were all completed independently by the participants. The assessors were blinded to baseline scores in order to ensure independent collection of outcome data.

\section{Stage 1 - Translation of the LLFI to the "LLFI-Sp"}

The primary objective of this aspect of the study was to ensure that the conceptual equivalence of the used terms was retained in a culturally Spanish-specific translation. A direct and reverse translation methodology was applied that involved two native English speakers for the 
direct translation and one native Spanish speaker for reverse translation. All were specialists in their field, as detailed and recommended in the specialized scientific literature (Figure 1) [44], and as performed in the cross-cultural adaptation to Spanish of other PRO tools [41]. The documents from Translators 1 and 2 showed minimally discernible differences that enabled the final consensus document to be rapidly achieved through a consensus approach of a unanimous agreement on the final version of each item between all translators (Figure 1).

\section{Stage 2 - Prospective Psychometric Investigation Participants, setting and procedure}

A total of 136 consecutive volunteers $(48 \pm 19$ years, $54.4 \%$ female) with a variety of chronic (>12 weeks duration) lower limb conditions were recruited from the Physical Therapy Outpatients Clinic at the Malaga University in Spain prior to treatment commencement. The criteria for inclusion were a lower limb injury and diagnosis by a medical practitioner. The chronic status was determined as $>12$ weeks duration [45] and that any acute treatment had been finalized when the participant was recruited. The chronic status was required as the WOMAC Spanish version had only been validated in chronic patients [20]. This also provided the additional validation of the LLFI in a chronic population as the

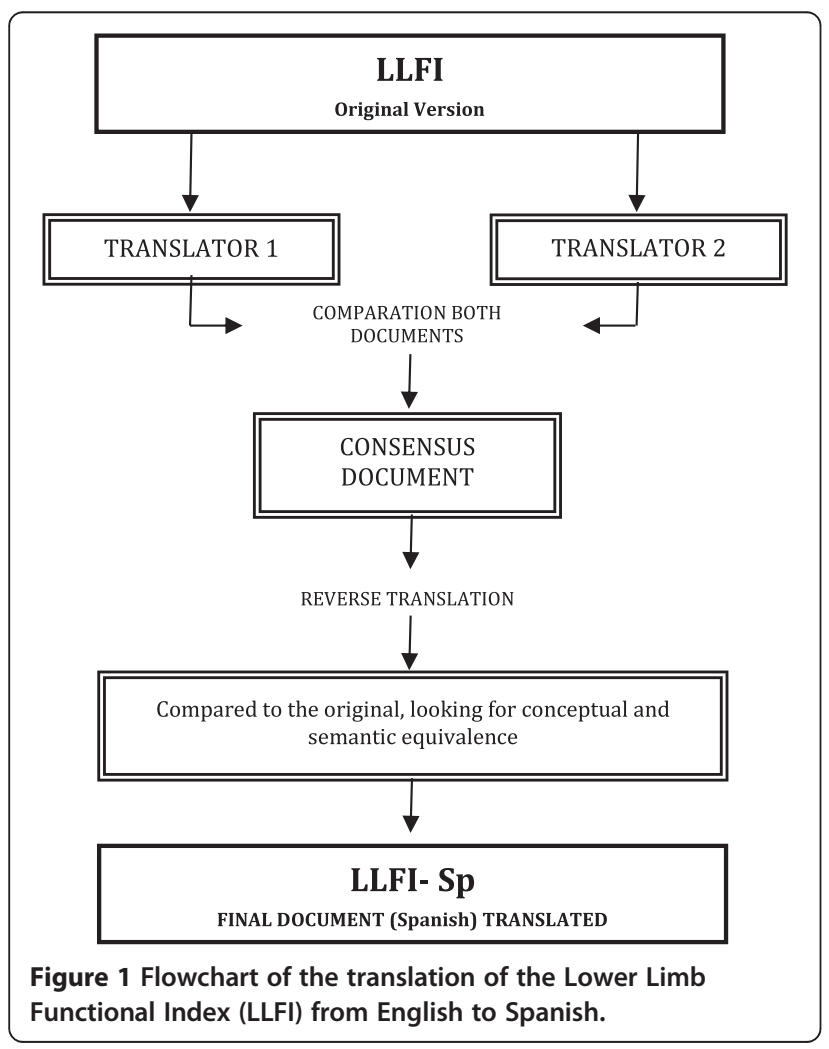

original study involved an acute population. The presenting conditions and diagnoses were broadly classified into six regional sub-categories (Table 1). The exclusion criteria were age $<18$ years and poor Spanish language comprehension as required for the completion of the questionnaires and assessed subjectively by the therapist in conjunction with the participant's feedback on comprehension ability. All participants with eligible criteria completed all three Spanish language self-administered questionnaires, the LLFI-Sp, WOMAC and the EQ-5D$3 \mathrm{~L}$, independently at baseline. Those involved in the reliability study provided a repeat score at day seven and completion of a 5-point global rating of change scale [46]. This study was conducted in accordance with the ethical principles for medical research involving human

Table 1 Demographic characteristics and frequency of diagnosis of the study population

\begin{tabular}{|c|c|c|}
\hline Characteristic & Cases (\%) & Age (years) Mean (sd) \\
\hline Study population & 136 & $48 \pm 19$ \\
\hline Male & $62(45.6 \%)$ & $50 \pm 20$ \\
\hline Female & $74(54.4 \%)$ & $46 \pm 25$ \\
\hline \multicolumn{3}{|l|}{ Subregion } \\
\hline Hip & 34 & $56 \pm 19$ \\
\hline - Bursa & 23 & \\
\hline - Capsule & 3 & \\
\hline - Impingement & 5 & \\
\hline - Other & 3 & \\
\hline Thigh & 8 & $38 \pm 21$ \\
\hline - Muscle strain & 7 & \\
\hline - Haematoma & 1 & \\
\hline Knee & 58 & $50 \pm 19$ \\
\hline - Ligament (MCL, LCL, ACL) & 33 & \\
\hline - PFJ & 22 & \\
\hline - Other & 3 & \\
\hline Calf and Shin & 9 & $32 \pm 23$ \\
\hline - Muscle strain & 7 & \\
\hline - Haematoma & 2 & \\
\hline Ankle & 12 & $46 \pm 19$ \\
\hline - Ligament & 10 & \\
\hline - Other & 2 & \\
\hline Foot & 6 & $50 \pm 21$ \\
\hline - Joint & 4 & \\
\hline - Other & 2 & \\
\hline Other & 9 & $59 \pm 21$ \\
\hline - Whole leg, & 6 & \\
\hline - Ulcers, & 1 & \\
\hline - Other & 2 & \\
\hline
\end{tabular}


subjects and approved in January 2011 by the ethics committee of the University of Malaga, (Spain).

The LLFI is a 25-item regional PRO with 3-point response options of 'Yes' (points $=1$ ), 'Partly' or 'Half' (points $=1 / 2$ ) and No' (points =0) with a raw score range of 0 to 25 points. It requires approximately two minutes to be completed. The score is calculated by simple addition of the responses then multiplied by four for conversion to a percentage scale or maximal loss of function. The total score subtracted from 100 gives a functional score as a percentage of pre-injury or normal status [7].

The WOMAC is a 24-item disease-specific questionnaire developed for patients with hip or knee osteoarthritis (OA). It requires approximately five minutes to be completed. It is a multidimensional scale grouped into three dimensions: pain (five items), stiffness (two items) and physical function (17 items). The version with five response levels for each item was used, scored from 0 to 4 , which represented different degrees of intensity. The final score in the Spanish version was validated as determined by adding the aggregate of the three dimensions scores $[19,20]$. The higher the score the worse the patient's condition with improvement indicated by an overall score reduction $[19,20]$. The data were standardized to a 100 percent scale where 0 represented optimal health and 100 the worst possible status. The original and Spanish questionnaires are both previously determined to be reliable, valid and sensitive to the changes in the health status of patients with hip or knee OA [18-20].

The EQ-5D-3 L is a widely used six-item non-diseasespecific questionnaire. It has five 3-point response options for different quality-of-life dimensions and a sixth question on overall perceived health-related status Visual Analogue Scale (VAS). The EQ-5D-3 L-VAS is used to reflect the respondent's self-rated health status on a $100 \mathrm{~mm}$ scale and ranked from 'Best Imaginable' (100) to Worst Imaginable' (0). The EQ-5D-3 L has been demonstrated as valid and reliable in the Spanish population [42].

Reliability was performed using the Intraclass Correlation Coefficient Type 2,1 ( $\left.\mathrm{ICC}_{2.1}\right)$ test-retest methodology in a randomly selected subgroup of the full sample. Randomization was performed by a computer generated list of numbers that was used against the patient participant number with no refusal or drop outs within in this reliability subgroup $(n=45,49 \pm 3$ years, $56.1 \%$ female). Their presenting conditions were verified as representative of the six area sub-categories of the full sample. The LLFI-Sp baseline and the repeated measures, taken at seven days [47] following a period during which there was no treatment, were both expressed with a $95 \%$ CI. To clarify that no change in status had occurred between the two measurement intervals a 5- point global rating of change was employed with a limitation of one scale point difference [46].

\section{Statistics}

Descriptive analyses were applied to calculate means and standard deviations of the demographic variables (Table 1). Distribution and normality were determined by the one-sample Kolmogorov-Smirnov tests. Construct validity was determined through the use of factor structure where a single factor structure would indicate that all items were reflective of the construct of interest lower limb functional status. Both construct validity and factor structure were determined from maximum likelihood extraction (MLE) with the a-priori extraction requirements being satisfaction of three critera: screeplot inflection, Eigenvalue $>1.0$ and variance $>10 \%$. We satisfied the recommended minimum ratio of five participantsper-item [48]. Exploratory factor analysis indicated a single factor structure was likely therefore more than 100 participants were required. The internal consistency was determined from Cronbach's $\alpha$ coefficient as calculated at an anticipated value range of 0.80-0.95 [49]. A student T-test was developed to check that items behaved the same way for males and females.

The sensitivity or measurement error score was determined from the $M D C_{90}$ analysis that was performed as described by Stratford [50]. The standard error of the measurement (SEM) was calculated using the formula: SEM $=s \sqrt{ }(1-r)$, where $s=$ standard deviation of the test scores (SD) of time 1 and time $2, r=$ the reliability coefficient for the test and Pearson's correlation coefficient between test and retest values [51]. To investigate statistical agreement between the test scores of Time 1 and time 2 a Bland-Altman test was also performed (Figure 2). Thereafter the $\mathrm{MDC}_{90}$ was calculated using the formula: $\mathrm{MDC}_{90}=\mathrm{SEM} \times \sqrt{ } 2 \times 1.65$.

Criterion validity was determined through the concurrent use of the WOMAC for specific criterion validity with the LLFI-Sp measure and with the EQ-5D-3 L total score and EQ-5D-3 L-VAS scores for criterion validity with general health status. The Pearson's $r$ correlation coefficient used the criteria of poor $(r<0.49)$, fair $(r=0.50-0.74)$ and strong $(r>0.75)$ [52].

The minimum sample sizes for the validation study were calculated from the original study where respectively criterion validity was determined through use of Meng's test of significance and solving for $\mathrm{n}$ [53] and reliability was determined from an $80 \%$ likelihood of detecting differences between the baseline and repeated measurements. Both calculations allowed for a 15\% attrition with $\mathrm{p}<0.05$ [44]. Power calculations indicated the need for a minimum sample of $n \geq 110$ for concurrent criterion validity and $n \geq 45$ for reliability [52]. 


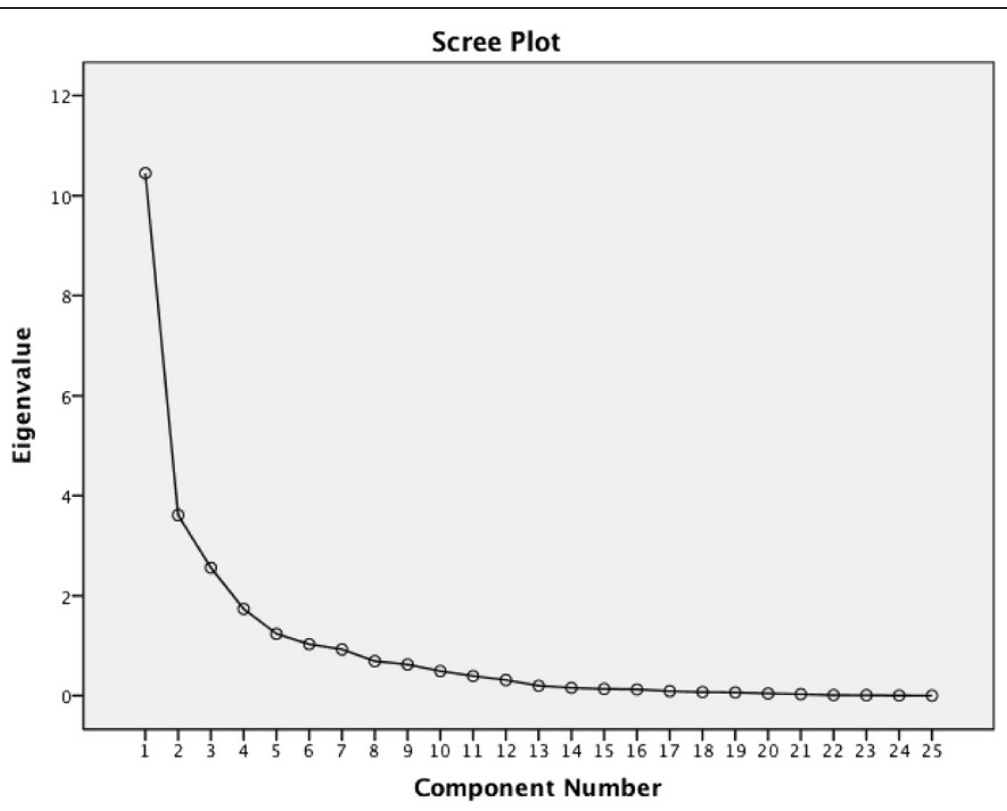

Figure 2 Blant-Altman plot for the test-retest reliability.

All statistical analyses were conducted using the Statistical Package for Social Science version 17.0 (SPSS 17.0) for Windows and LISREL 8.80 [54].

\section{Results}

The demographic and frequency of diagnosis of the sample are detailed in Table 1. The LLFI was translated and back translated with consideration of the Spanish cultural linguistic adaptation to provide the new LLFI-Sp questionnaire without language difficulties or other conceptual misunderstanding (Additional file 1). The mean and standard deviation for LLFI-Sp score were determined (5.88 \pm 5.6 points), there were no missing responses and a high degree of internal consistency $(\alpha=0.91)$ was demonstrated with an item range of 0.88 to 0.95 .

The test-retest reliability was high at $(\mathrm{ICC}=0.96)$ with a range of 0.93 to 0.97 . Measurement error from SEM and $\mathrm{MDC}_{90}$ were respectively $3.12 \%$ and $7.12 \%$. No significance gender differences were found in the item responses. The Bland-Altman plot showed a high level of agreement between the test scores at Time 1 and 2 (Figure 2).

For factor analysis the correlation matrix for the LLFI-Sp was determined as suitable from the Kaiser-Meyer-Oklin values $(0.86)$ and Barlett's Test of Sphericity $(\mathrm{p}<0.001)$. This indicated that the correlation matrix was unlikely to be an identity matrix and was therefore suitable for MLE. The a-priori requirements for one-dimensional factor structure were verified. The screeplot (see Figure 3) indicated a one-factor solution when all three a-priori factors were accounted for. The factor analysis revealed a satisfactory percentage of total variance explained by the one factor at $22.8 \%$. It was noted that eight factors had Eigenvalues $>1.0$ and accounted for $65.4 \%$ of variance; however those with an Eigenvalue $>1.0$ each accounted for $<10 \%$ of variance and were shown to be after the screeplot initial inflection point (Figure 3) and consequently not extracted. The item loading for the one-factor solution for the MLE method and average score for each item is shown in Table 2.

Criterion validity determined from the relationship between the LLFI-Sp and WOMAC was strong $(\mathrm{r}=0.77)$ but fair and inversely related for the LLFI-Sp and the EQ-5D-3 L $(r=-0.62)$ and EQ-5D-3 L-VAS $(r=-0.58)$.

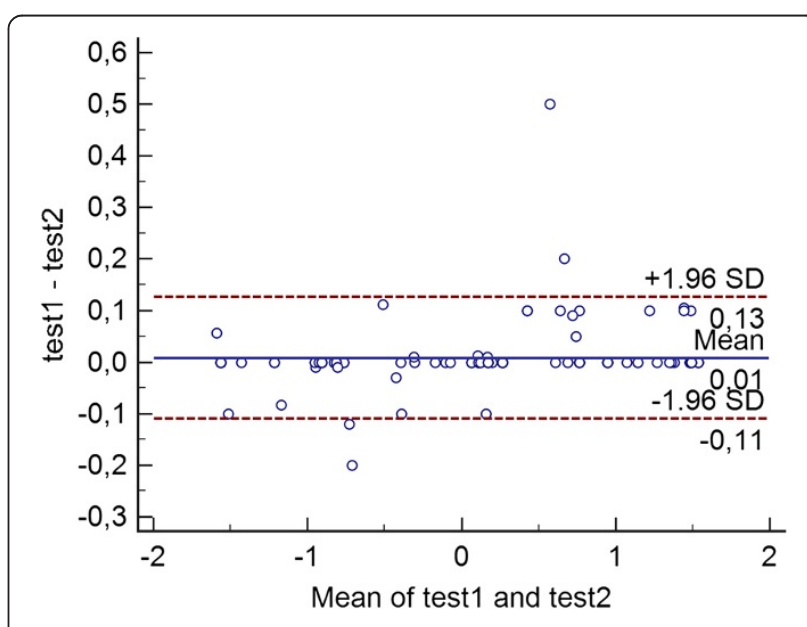

Figure 3 Scree plot of the exploratory one-factor solution. 
Table 2 Factor loading items for the one-factor solution, average score and discrimination indices of items ( $\mathbf{n}=136$ )

\begin{tabular}{|c|c|c|c|c|}
\hline Question & Item & Factor loading & Item average score & Item discr. indices \\
\hline 1 & Stay at home most of time & .780 & .25 & $.259^{*}$ \\
\hline 2 & Change positions frequently & .703 & .38 & $.811^{* *}$ \\
\hline 3 & Avoid heavy jobs & .466 & .75 & $.561^{* *}$ \\
\hline 4 & Rest more often & .691 & .75 & $.388^{*}$ \\
\hline 5 & Get others to do things & .726 & .38 & $.656^{* *}$ \\
\hline 6 & Pain almost all the time & .690 & .38 & $.822^{* *}$ \\
\hline 7 & Lifting and carrying & .735 & .75 & $.561^{*}$ \\
\hline 8 & Appetite affected & .740 & .13 & $.334^{*}$ \\
\hline 9 & Walking/normal recreation/sport & .796 & .75 & $.561^{* *}$ \\
\hline 10 & Home/family duties and chores & .514 & .38 & $.665^{* *}$ \\
\hline 11 & Sleep less well & .607 & .38 & $.622^{* *}$ \\
\hline 12 & Assistance with personal care, hygiene & .706 & .13 & $.690^{* *}$ \\
\hline 13 & Regular daily activity work/social & .601 & .63 & $.811^{* *}$ \\
\hline 14 & More irritable/bad tempered & .497 & .13 & $.776^{* *}$ \\
\hline 15 & Feel weaker or stiffer & .838 & .25 & $.622^{* *}$ \\
\hline 16 & Transport independence & .687 & .13 & $.863^{* *}$ \\
\hline 17 & Difficulty or need with dressing (e.g. trousers/pants/shoes and socks) & .849 & .25 & $.480^{*}$ \\
\hline 18 & Difficulty changing directions, twisting or turning. & .429 & .25 & $.509^{*}$ \\
\hline 19 & Unable to move as fast as I would wish. & .664 & .50 & $.209^{*}$ \\
\hline 20 & I have difficulty with prolonged or extended standing. & .658 & .50 & $.863^{* *}$ \\
\hline 21 & Difficulty bending, squatting and/or reaching down. & .645 & .63 & $.767^{* *}$ \\
\hline 22 & Difficulty with long or extended walks. & .249 & .63 & $.523^{*}$ \\
\hline 23 & Difficulty with steps and stairs. & .471 & .88 & $.624^{* *}$ \\
\hline 24 & Difficulty with sitting for prolonged or extended times. & .620 & .25 & $.782^{* *}$ \\
\hline 25 & $\begin{array}{l}\text { Problems with my balance on uneven surfaces and / or with } \\
\text { unaccustomed footwear. }\end{array}$ & .394 & .63 & $.803^{* *}$ \\
\hline
\end{tabular}

${ }^{*} \mathrm{p}<0.05$.

${ }^{* *} \mathrm{p}<0.01$.

\section{Discussion}

\section{Main findings}

The LLFI was translated to provide a cross-cultural adaptation to the Spanish language. The translation process ensured the conceptual equivalence of the used terms. This provided accessibility to the LLFI for the second largest geographically used language. The psychometric properties, specifically construct and criterion validity, reliability and internal consistency were determined and found to be strong and the single factor structure indicated a single summated score could be used [36].

The cross-cultural adaptation of the LLFI into Spanish enables clinicians in Spanish speaking settings to compare outcomes following their treatments and interventions affecting the lower limb. The procedure of cross-cultural adaptation of a scale has been used in previous studies for different scales to be applied in the Spanish context $[43,44]$. It is critical to employ research measures that are valid and reliable but they must also be both culturally and linguistically appropriate [41].

The one-factor solution that emerged in the factor analysis accounted for a significant proportion of variance. Though this value is lower than the $30.3 \%$ found in the original study it is still an acceptable level for a 25-item questionnaire [52]. This evidence also supports the presence of construct validity. A one-factor solution is critical if a PRO is to be used with a single summated score [36], and subsequently reflect the construct for which it is primary used [6] - that of representation of the functional status of the lower limb as a single kinetic chain [7].

Four further critical psychometric properties of the LLFI-Sp were shown to be well supported. The internal consistency analysis at $\alpha=0.91$ was identical to that of the original English version [7], which sits below the accepted 0.95 thresholds for item redundancy [36]. The test-retest reliability or reproducibility $(r=0.96$ and 
Figure 2) was also equivalent to the original instrument (0.97) [7]. The criterion validity with the WOMAC was demonstrated as strong $(r=0.77)$ suggesting transferability and substitution may be an option. This is supported by the remaining psychometric factors that are preferable and that the LLFI was designed as a lower limb regional tool rather than a joint or condition specific measure, as was the case for the WOMAC. The EQ-5D-3 L was fair and inversely correlated $(r=-0.62)$ but at a lower level suggesting substitution for general health measurement and vice versa is unlikely to be appropriate. The directional trend however supports the construct validity and the determination of the LLFI-Sp as appropriate in terms of face and content validity as a deteriorating health correlates to worsening function. The level of measurement error with an $\mathrm{MDC}_{90}$ of $7.12 \%$ was comparable that larger than that of the original LLFI at $6.6 \%$.

\section{Study strengths and limitations}

The strengths of the study include the prospective nature and the adequate number of subjects that provided a suitable sample size and power of analysis. The inclusion of consecutive patients, independence of the assessors and referral source as well as the broad diagnosis and category representations suggests limited selection bias and the potential for population generalizability [48]. The results for the psychometric properties support the findings of the previous research on the original English version of the LLFI indicating broad cross-cultural adaptions would be appropriate to other diverse socioeconomic, cultural and linguistic groups. The LLFI-Sp also provides a means of comparing lower limb health status in Spanish-speaking patients with their English-speaking counterparts in countries with a high Spanish-speaking population such as the United States.

The study limitations include the lack of longitudinal data regarding other psychometric properties, including responsiveness or sensitivity to change, and a minimal clinically important difference. Also face and content validity which should also be performed in a translated instrument were not determined within a patient focus subgroup but from the transilational aspects only. The translation process ensured the conceptual equivalence of the used terms, however only the translators and no with cognitive interviews tested this before validation. The determination of construct validity through the use of factor analysis represents only one possible statistical method of testing this property. A construct is not restricted to one set of observable indicators or attributes and additional indicators will require consideration in future research. Similarly, the practical characteristics were not determined. The results are applicable only to the Spanish speaking population from Spain. The inclusion of Hispanic/Latino/South American participants in future studies could potentially provide confirming or conflicting linguistic information due to the cultural and ethnic difference with respect to the Spanish participants and their cultural diversity in terms of European versus the Americas, North, Central and South.

\section{Conclusions}

The LLFI is translated and cross-culturally adapted to Spanish for the first time. The psychometric properties of this LLFI Spanish version are also reported with the determined values found to be satisfactory and supportive of the findings of the LLFI scale in the English format, particularly in the areas of internal consistency, reliability, factor structure and error score. Consequently the LLFI-Sp may be useful in Spanish-speaking populations and for making cross-ethnic and cross-cultural comparisons in other English speaking countries with a high Spanish-speaking population.

\section{Additional file}

Additional file 1: The Spanish version of the Lower Limb functional index.

\section{Competing interest}

The authors declare that they have no competing interests.

\section{Authors' contributions}

All the authors have made contributions to conception of this study. AIC-V and PCG participated in the analysis and interpretation of data and were involved in drafting the manuscript or revising it critically for important intellectual content. All the authors have given final approval of the version to be published.

\section{Acknowledgments}

The authors are grateful to the volunteers for their participation and the PMDT, Malaga. This study received a grant from the Research Office of the University of Malaga.

\section{Author details}

'Departamento de Psiquiatría y Fisioterapia, Facultad de Ciencias de la Salud, Universidad de Malaga, Andalucia Tech, Instituto de Biomedicina de Malaga (IBIMA), Grupo de Clinimetria (AE-14), Málaga, Spain. ${ }^{2}$ School of Clinical Science, Faculty of Health at the Queensland University of Technology, Brisbane, Australia. ${ }^{3}$ Centre for Healthy Activities, Sport and Exercise of the Faculty of Science at the University of the Sunshine Coast Queensland, Marochydore, Queensland, Australia.

Received: 24 February 2014 Accepted: 10 May 2014 Published: 17 May 2014

\section{References}

1. Garratt A: Patient reported outcome measures in trials, editorial. BMJ 2009, 338:2597.

2. Cella D, Yount S, Rothrock N, Gershon R, Cook K, Reeve B, Ader D, Fries JF, Bruce B, Rose M: PROMIS cooperative group. The patient-reported outcomes measurement information system (PROMIS): progress of an $\mathrm{NIH}$ roadmap cooperative group during its first Two years. Med Care 2007, 45(5):S3-S11.

3. Fayers PM, Machin D: Quality of Life: Assessment, Analysis and Interpretation of Patient-reported Outcomes. 2nd edition. Chichester: Wiley; 2000.

4. Morris $L A$, Miller DW: The regulation of patient-reported outcome claims: need for a flexible standard. Value Health 2002, 5:372-381. 
5. Beaton DE, Schemitsch E: Measures of health-related quality of life and physical function. Clin Orthop Relat Res 2003, 413:90-105.

6. Terwee CB, Bot SD, de Boer MR, van der Windt DA, Knol DL, Dekker J, Bouter LM, de Vet HC: Quality criteria were proposed for measurement properties of health status questionnaires. J Clin Epidemiol 2007, 60:34-42.

7. Gabel CP, Melloh M, Burkett B, Michener LA: Lower Limb Functional Index: development and clinimetric properties. Phys Ther 2012, 92:98-110.

8. Oberg U, Oberg B, Oberg T: Validity and reliability of a new assessment of lower extremity dysfunction. Phys Ther 1994, 74:861-871.

9. Gabel CP, Melloh M, Burkett B, Michener LA: A new outcome measure for the whole-spine demonstrates improved performance, clinimetric properties and practicality. Spine J 2013, doi:10.1016/j.spinee.2013.09.055.

10. Binkley JM, Stratford PW, Lott SA, Riddle DL: The lower extremity functional scale (LEFS): scale development, measurement properties, and clinical application. Phys Ther 1999, 79:371-383.

11. Johanson NA, Liang MH, Daltroy L, Johanson NA, Liang MH, Daltroy L, Rudicel S, Richmond J: American academy of orthopaedic surgeons lower limb outcomes assessment instruments: reliability, validity, and sensitivity to change. J Bone Joint Surg Am 2004, 86:902-909.

12. Martin RL, Irrgang JJ, Burdett RG, Martin RL, Irrgang JJ, Burdett RG, Conti SF, Van Swearingen JM: Evidence of validity for the foot and ankle ability measure (FAAM). Foot Ankle Int 2005, 26:968-983.

13. Lequesne MG, Mery C, Samson M, Gerard P: Indexes of severity for osteoarthritis of the hip and knee. Scand J Rheumatol 1987, 65(Suppl):85-9.

14. Nilsdotter AK, Lohmander LS, Klässbo M, Roos EM: Hip disability and osteoarthritis outcome score (HOOS)-validity and responsiveness in total hip replacement. BMC Musculoskelet Disord 2003, 4:10.

15. Roos EM, Roos HP, Lohmander LS, Ekdahl C, Beynnon BD: Knee injury and osteoarthritis outcome score (KOOS) - development of a selfadministered outcome measure. J Orthop Sports Phys Ther 1998, 28:88-96.

16. Wright JG, Young NL: The patient-specific index: asking patients what they want. J Bone Joint Surg Am 1997, 79:974-83.

17. Meenan RF, Gertman MP, Mason JH: Measuring health status in arthritis. The arthritis impact measurement scales. Arthritis Rheum 1980, 23:146-52.

18. Bellamy N, Buchanan WW, Goldsmith CH, Campbell J, Stitt LW: Validation study of WOMAC: a health status instrument for measuring clinically important patient relevant outcomes to antirheumatic drug therapy in patients with osteoarthritis of the hip or knee. J Rheumatol 1988, 15:1833-40

19. Batlle-Gualda E, Esteve-Vives J, Piera MC, Hargreaves R, Cutts J: Tradución y adaptación al español del cuestionario WOMAC específico para artrosis de rodilla y cadera. Rev Esp Reumatol 1999, 26:38-45.

20. Escobar A, Quintana JM, Bilbao A, Azkárate J, Güenaga Jl: Validation of the Spanish version of the WOMAC questionnaire for patients with hip or knee osteoarthritis. Western Ontario and McMaster universities osteoarthritis index. Clin Rheumatol 2002, 21(6):466-71.

21. Button G, Pinney S: A meta-analysis of outcome rating scales in foot and ankle surgery:is there a valid, reliable, and responsive system? Foot Ankle Int 2004, 25:521-525.

22. Peterson MG, Blake VA, Allegrante JP, Johanson NA, Mancuso CA, Robbins L, Ranawat CS, Charlson ME: A comparison of self-reported hip symptomatology in hip replacement patients and a population-based sample of medicare beneficiaries. Med Sci Monit 2004,

10(7):CR275-81. Epub 2004 Jun 29.

23. Eechaute $C$, Vaes $P$, Van Aerschot $L$, Eechaute $C$, Vaes $P$, Van Aerschot $L$, Asman S, Duquet W: The clinimetric qualities of patient assessed instruments for measuring chronic ankle instability: a systematic review. BMC Musculoskelet Disord 2007, 8:6.

24. Riddle DL, Stratford PW, Bowman DH: Findings of extensive variation in the types of outcome measures used in hip and knee replacement clinical trials: a systematic review. Arthritis Rheum 2008, 59:876-883.

25. Naal FD, Impellizzeri FM, Rippstein PF: Which are the most frequently used outcome instruments in studies on total ankle arthroplasty? Clin Orthop Relat Res 2010, 468:815-826.

26. Eng JJ, Pierrynowski MR: Evaluation of soft foot orthotics in the treatment of patellofemoral pain syndrome [erratum in: Phys Ther. 1993;73:330]. Phys Ther 1993, 73:62-68.

27. Flandry F, Hunt JP, Terry GC, Hughston JC: Analysis of subjective knee complaints using visual analog scales. Am J Sports Med 1991, 19:112-118.
28. Hawker G, Melfi C, Paul J, Green R, Bombardier C: Comparison of a generic (SF-36) and a disease specific (WOMAC) (Western Ontario and McMaster Universities Osteoarthritis Index) instrument in the measurement of outcomes after knee replacement surgery. J Rheumatol 1995, 22:1193-1196

29. Mohtadi N: Development and validation of the Quality Of Life Outcome Measure (Questionnaire) for chronic anterior cruciate ligament deficiency. Am J Sports Med 1998, 26:350-359.

30. Barber FA, Aziz-Jacobo J, Oro FB: Anterior cruciate ligament reconstruction using patellar tendon allograft: an age dependent outcome evaluation. Arthroscopy 2010, 26:488-493

31. Kujala UM, Jaakkola LH, Koskinen SK, Kujala UM, Jaakkola LH, Koskinen SK Taimela S, Hurme M, Nelimarkka O: Scoring of patellofemoral disorders. Arthroscopy 1993, 9:159-163.

32. Robinson JM, Cook JL, Purdam C, Robinson JM, Cook JL, Purdam C, Visentini PJ, Ross J, Maffulli N, Taunton JE, Khan KM, Victorian Institute Of Sport Tendon Study Group: The VISA-A questionnaire: a valid and reliable index of the clinical severity of Achilles tendinopathy. $\mathrm{Br} J$ Sports Med 2001, 35:335-341.

33. White DK, Keysor JJ, Lavalley MP, White DK, Keysor JJ, Lavalley MP, Lewis CE, Torner JC, Nevitt MC, Felson DT: Clinically important improvement in function is common in people with or at high risk of knee OA: the MOST study. J Rheumatol 2010, 37:1244-1251.

34. Stratford P, Kennedy D, Hanna SE: Condition-specific Western Ontario Mc- Master Osteoarthritis Index was not superior to region-specific Lower Extremity Functional Scale at detecting change. J Clin Epidemiol 2004, 57:1025-1032.

35. Roh YH, Kim KW, Paik NJ, Kim TK, Gong HS: How much Are upper or lower extremity disabilities associated with general health status in the elderly? Clin Orthop Relat Res 2012, 470:3246-3252.

36. Doward LC, McKenna SP: Defining patient-reported outcomes. Value Health 2004, 7:4-8.

37. Williams VJ, Piva SR, Irrgang JJ, Crossley C, Fitzgerald GK: Comparison of reliability and responsiveness of patient-reported clinical outcome measures in knee osteoarthritis rehabilitation. J Orthop Sports Phys Ther 2012, 42:716-723.

38. PROQoLD. website [http://www.progolid.org/instruments/lower_limb_functional_ index Ifi?fromSearch=yes\&text=yes]

39. World Health Organisation (WHO): International Classification of Functioning, Disability and Health (ICF). World Health Organisation (WHO) Geneva 2001. Available at: http://www.who.int/classifications/icf/en/ (accessed July 31 2009)

40. Gabel CP, Michener LA, Melloh M, Burkett B: Modification of the upper limb functional index to a three-point response improves clinimetric properties. J Hand Ther 2010, 23:41-52.

41. Cuesta-Vargas A, Gabel C: Cross-cultural adaptation, reliability and validity of the Spanish version of the upper limb functional index. Health Qual Life Outcomes 2013, 11:126.

42. ONU: Paises de habla hispana promueven uso del español en la ONU. http://www.un.org/spanish/News/fullstorynews.asp?newsID=6370\& criteria $1=$ cultura

43. Badía X, Roset M, Montserrat S, Herdman M, Segura A: The Spanish version of EuroQoL: A description and its applications. European Quality of Life scale. Med Clin (Barc) 1999, 112:79-85.

44. Muñiz J, Elosua P, Hambleton RK: International Test Commission Guidelines for test translation and adaptation: Second edition. Psicothema 2013, 25:151-157.

45. van Tulder M, Becker A, Beckering T, van Tulder M, Becker A, Bekkering T, Breen A, del Real MT, Hutchinson A, Koes B, Laerum E, Malmivaara A, COST B13 Working Group on Guidelines for the Management of Acute Low Back Pain in Primary Care: Chapter 3. European guidelines for the management of acute nonspecific low back pain in primary care. Eur Spine J 2006, 15:S169-91.

46. Vet HC, Ostelo RW, Terwee CB, van der Roer N, Knol DL, Beckerman H, Boers M, Bouter LM: Minimally important change determined by a visual method integrating an anchor-based and a distribution-based approach. Qual Life Res 2007, 16:131-142.

47. Terwee CB, Mokkink LB, Knol DL, Ostelo RW, Bouter LM, de Vet HC: Rating the methodological quality in systematic reviews of studies on measurement properties: a scoring system for the COSMIN checklist. Qual Life Res 2012, 21:651-7.

48. Kass RA, Tinsley HEA: Factor analysis. J Leisure Res 1979, 11:120-138. 
49. Cronbach $\sqcup$ : Coefficient alpha and the internal structure of tests. Psychometrika 1951, 16:297-334.

50. Stratford PW: Getting more from the Literature: estimating the standard error of measurement from reliability studies. Physiother Can 2004, 56:27-30

51. Harvill LM: Standard Error of Measrument. An NCME Instructional Module. East Tennessee State University; 1991:33-41.

52. Field A: Discovering Statistics using SPSS. London: SAGE Publications Ltd; 2005.

53. Meng $X$, Rosenthal R, Rubin DB: Comparing correlated correlation coefficients. Psychol Bull 1992, 111:172-5.

54. Jöreskog KG, Sörbom D: LISREL 8.80. Chicago: Scientific Software International; 2007.

doi:10.1186/1477-7525-12-75

Cite this article as: Cuesta-Vargas et al:: Cross cultural adaptation and validation of a Spanish version of the lower limb functional index. Health and Quality of Life Outcomes 2014 12:75.

\section{Submit your next manuscript to BioMed Central and take full advantage of:}

- Convenient online submission

- Thorough peer review

- No space constraints or color figure charges

- Immediate publication on acceptance

- Inclusion in PubMed, CAS, Scopus and Google Scholar

- Research which is freely available for redistribution 